\title{
Effect of Interfacial Reaction on the Mechanical Performance of Steel to Aluminum Dissimilar Ultrasonic Spot Welds \\ Dol:
}

10.1007/s11661-015-3179-7

\section{Document Version}

Accepted author manuscript

Link to publication record in Manchester Research Explorer

Citation for published version (APA):

Xu, L., Wang, L., Chen, Y-C., Robson, J., \& Prangnell, P. (2016). Effect of Interfacial Reaction on the Mechanical Performance of Steel to Aluminum Dissimilar Ultrasonic Spot Welds. Metallurgical and Materials Transactions A Physical Metallurgy and Materials Science, 47(1), 334-346. https://doi.org/10.1007/s11661-015-3179-7

Published in:

Metallurgical and Materials Transactions A - Physical Metallurgy and Materials Science

\section{Citing this paper}

Please note that where the full-text provided on Manchester Research Explorer is the Author Accepted Manuscript or Proof version this may differ from the final Published version. If citing, it is advised that you check and use the publisher's definitive version.

\section{General rights}

Copyright and moral rights for the publications made accessible in the Research Explorer are retained by the authors and/or other copyright owners and it is a condition of accessing publications that users recognise and abide by the legal requirements associated with these rights.

\section{Takedown policy}

If you believe that this document breaches copyright please refer to the University of Manchester's Takedown Procedures [http://man.ac.uk/04Y6Bo] or contact uml.scholarlycommunications@manchester.ac.uk providing relevant details, so we can investigate your claim.

\section{OPEN ACCESS}




\title{
Effect of Interfacial Reaction on the Mechanical Performance of Steel to Aluminum Dissimilar Ultrasonic Spot Welds
}

\author{
Lei Xu ${ }^{1}$, Li Wang ${ }^{2}$, Ying-Chun Chen ${ }^{3}$, Joe D Robson ${ }^{1}$, Philip B Prangnell ${ }^{1 *}$ \\ ${ }^{1}$ School of Materials, University of Manchester, Manchester, M13 9PL, UK \\ 2Jaguar Land Rover Jaguar, Engineering Centre, Abbey Road, Whitley, Coventry, CV3 4LF UK. \\ ${ }^{3}$ The Manufacturing Technology Centre, Pilot Way, Ansty Business Park, Coventry, CV7 9JU, UK. \\ lei.xu-2@postgrad.manchester.ac.uk, Iwang9@jaguarlandrover.com, yingchun.chen@the-mtc.org, \\ joseph.d.robson@manchester.ac.uk, philip.prangnell@manchester.ac.uk \\ ${ }^{*}$ Corresponding author
}

Keywords: Ultrasonic Welding; Dissimilar Welding, Steel, Aluminum, Interfacial reaction, intermetallic compounds

\begin{abstract}
The early stages of formation of intermetallic compounds (IMC) have been investigated in dissimilar aluminum to steel welds, manufactured by high power ( $2.5 \mathrm{~kW})$ ultrasonic spot welding (USW). To better understand the influence of alloy composition, welds were produced between a low-carbon steel (DC04) and two different aluminum alloys (6111 and 7055). The joint strengths were measured in lap shear tests and the formation and growth behavior of IMCs at the weld interface characterized by electron microscopy, for welding times from 0.2 to 2.4 seconds. With the material combinations studied, the $\eta\left(\mathrm{Fe}_{2} \mathrm{Al}_{5}\right)$ intermetallic phase was found to form first, very rapidly in the initial stage of welding, with a discontinuous island morphology. Continuous layers of $\eta$ and then $\theta\left(\mathrm{FeAl}_{3}\right)$ phase were subsequently seen to develop on extending the welding time to greater than 0.7 seconds. The IMC layer formed in the DC04-AA7055 combination grew thicker than for the DC04-AA6111 welds, despite both weld sets having near identical thermal histories. Zinc was also found to be dissolved in the IMC phases when welding with the AA7055 alloy. After post-weld ageing of the aluminum alloy, fracture in the lap shear tests always occurred along the joint interface; however, the DC04-AA6111 welds had higher fracture energy than the DC04-AA7055 combination.
\end{abstract}

Key words: ultrasonic spot welding (USW); dissimilar Fe-Al welding; intermetallic compounds (IMC) 


\section{Introduction}

Owing to the growing environmental pressure to reduce the weight of vehicles, there is considerable interest in the production of more mass efficient multi-material structures by combing aluminum and steel in advanced automotive construction ${ }^{[1-5]}$. Unfortunately, conventional fusion welding processes do not currently meet industrial requirements for dissimilar metal joining. This is primarily because a high rate of intermetallic reaction occurs in the liquid phase, which leads to poor properties and, in particular, low joint fracture toughness levels ${ }^{[1-3]}$. High power Ultrasonic Spot Welding (USW) is a promising new solid-state process that could potentially be substituted for resistance spot welding and can reduce the tendency for intermetallic formation, because no liquid phase is generated ${ }^{[5-8]}$. However, the success of any new dissimilar joining technology is also dependent on other considerations such as the operating costs, cycle time, reliability, and weld quality ${ }^{[7-9]}$. Previous studies ${ }^{[5-10]}$ have demonstrated that even with a rapid solidstate welding process, like USW, one of the most critical issues is still controlling the intermetallic reaction that occurs at the weld interface. This is because intermetallic compounds (IMCs) are very brittle and a continuous IMC interface layer severely compromises the joints fracture energy if it becomes greater than $100 \mathrm{~nm}$ thick ${ }^{[2-10]}$.

Although it is thermodynamically possible to produce a range of intermetallic compounds in the Al-Fe system ${ }^{[10,11]}$, the $\eta\left(\mathrm{Fe}_{2} \mathrm{Al}_{5}\right)$ phase is most predominantly reported in aluminum - steel dissimilar welds made with both friction and fusion processes ${ }^{[12-17]}$. This is thought to be partly due to a favored crystallographic habit orientation with ferrite $\left([110]_{\eta} / /[111]_{\mathrm{Fe}},(001)_{\eta} / /(011)_{\mathrm{Fe}}(110)_{\eta} / /(211)_{\mathrm{Fe}}.\right)$ which facilitates nucleation of $\eta^{[4]}$. To date, most of the research that has studied IMC reaction kinetics in Al-Steel couples has focused on the growth rate of continuous IMC layers developed after long welding times, or

extended isothermal treatments ${ }^{[22-25]}$. In contrast, industrial spot welding typically takes place in less than one second. It is therefore important to systematically investigate the early stages of IMC formation at short weld durations and, in particular, when the reaction layer is still discontinuous at the weld interface. In addition, it has been shown in USW that the growth rate of IMC layers can be abnormally rapid (compared with that observed in a static diffusion couple) as the high strain rate deformation that occurs during the welding process can accelerate diffusion along the IMC interface and damage the reaction layer, which reduces its effectiveness as a diffusion barrier ${ }^{[6-7]}$. It is also known that in dissimilar welding the 
composition of the weld members can strongly affect intermetallic phase formation at the joint interface (e.g. [25], [26]), although the relationship to many common alloy additions still remains poorly understood.

To shed further light on the influence of some of these important factors, on the potential for producing high integrity joints by USW of steel to aluminum, two different aluminum alloys have been used to study the effect of changing alloy composition on the early stages of IMC formation and the consequent mechanical performance of the welds produced. The AA6111 and AA7055 alloys chosen for this investigation were selected because they are typical of age-hardenable aluminum alloys used in the automotive and aerospace industries, respectively ${ }^{[5-7,26-30]}$.

\section{Experimental}

\subsection{Materials}

Ultrasonic spot welds were produced between a DC04, 0.08\% carbon, formable, automotive steel and two aluminum alloys (AA6111 and AA7055) using $25 \times 100 \mathrm{~mm}$ rectangular coupons, cut from $1 \mathrm{~mm}$ thick sheets (see Fig. 1). Welding was performed with the aluminum alloys in a solution treated condition. The chemical compositions of the materials used are given in Table 1. Prior to welding, the sheet surfaces were prepared by grinding with \#120 grit SiC paper and then cleaning in acetone. The welds were produced with a Sonobond dual-head spot welding system at the center of a $25 \mathrm{~mm}$ overlap (shown in Fig. 1). The welding system operated at $21 \mathrm{kHz}$ and the joints were produced using a nominal applied power of $2.5 \mathrm{~kW}$, with a clamping pressure of $1.4 \mathrm{kN}$. All the welding parameters are provided in Table 2. A flat $8 \times 6 \mathrm{~mm}$ rectangular sontrode tip was used on the aluminum side of the joint, while the tip on the steel side had a $5 \mathrm{~mm}$ radiuses surface. Both tips had a parallel knurl pattern on their surfaces with a pitch of $1 \mathrm{~mm}$ (see Fig $1 \mathrm{~b}$ ).

Following welding, artificial ageing was carried out to obtain T6 tempers in both aluminum alloys. For the AA6111-DC04 combination this involved heat treating for 24 hours at $453 \mathrm{~K}\left(180^{\circ} \mathrm{C}\right)^{[31]}$, while for the AA7055- DC04 joints, ageing was performed at $273 \mathrm{~K}\left(100^{\circ} \mathrm{C}\right)$ for 8 hours, followed by 24 hours at $393 \mathrm{~K}$ $\left(120^{\circ} \mathrm{C}\right)^{[32]}$. Long term isothermal annealing was also applied to lightly pre-welded weld couples (weld time 1 second) at $723 \mathrm{~K}\left(450^{\circ} \mathrm{C}\right)$ to compare the growth rates of the IMC layer in both material combinations. 


\subsection{Microstructural Characterization}

Metallographic cross-sections were prepared from the welds by grinding and polishing using standard techniques, prior to observation by scanning electron microscopy (SEM). Back scatter imaging in a Philips XL 30 and FEI Quanta 650 microscopes was used to study the IMC layer growth behavior at the center of the weld area and measure the layer thickness. The average layer thickness was determined from the net area of the IMC layer seen in a 2D metallographic section divided by the interface length. This method was employed as for short welding times the layer was not uniform in thickness.

Electron Back Scatter Diffraction (EBSD) with a crystallographic electron diffraction database was used to identify the phases within the IMC layer and determine their grain structure and microtexture. This analysis was performed on weld cross sections using a high resolution FEI Megallan FEG microscope, following final ion beam polishing in a Gatan Ilion ${ }^{\mathrm{TM}}$ system. TEM was also used to confirm the crystal structures and compositions of the IMC phases present at the interface samples and to check for the presence of minor phases not resolvable by SEM. TEM samples were prepared from selected positions using a Novalab 660 Focussed Ion Beam (FIB) with a Ga ${ }^{+}$ion accelerating voltage of $30 \mathrm{kV}$. Analysis was performed using an FEI Tecnai TF30 microscope operating at $300 \mathrm{kV}$.

\subsection{Mechanical Testing}

Lap shear testing of the weld samples was performed using an MTS Alliance RT-100 mechanical testing machine with a $50 \mathrm{kN}$ load cell. Metal shims that matched the sheet thickness were used to ensure axial loading. All tests were performed at a crosshead travel speed on $0.5 \mathrm{~mm} \mathrm{~min}^{-1}$. Three tests were carried out for each welding condition and only the average values are reported in this study. Both the peak failure loads $(\mathrm{kN})$ and the fracture energy $(\mathrm{kN} . \mathrm{mm})$ were used to compare the joint performance. The fracture energy was estimated from the integrated area under the load displacement curves in the lap shear tests. This is an acceptable definition but quite a crude measurement and is fully defined in the method. After testing, the fracture surfaces were investigated by SEM and energy-dispersive X-ray spectroscopy (EDX). 


\subsection{Temperature measurement}

Thermocouple measurements were made during USW to determine the interface temperature histories, for different welding times. For each welding condition, welds were produced with a $0.5 \mathrm{~mm}$ wire diameter K-type thermocouples placed between the lapped aluminum and steel sheets. The thermocouples were insulated with PTFE tape and inserted through a small channel in the aluminum sheet, transverse to the vibration direction, to the center of welding area prior to welding, with the tip at the center of the spot area. The thermocouples became integrated into the weld, as shown in Fig. 1 (c). The peak temperatures recorded were the average of three tests where the location of the thermocouples' tip was confirmed to be in the center of the welding area by post weld metallographic sectioning.

\section{Results}

\subsection{Temperature histories}

Fig. 2 (a) shows examples of typical temperature histories measured from each joint interface, at the center of the weld area, and the average peak temperatures reached with increasing welding times are summarized in Fig. 2 (b). The thermal data was only used if, in post-weld sample sectioning, the position of each thermocouple after welding was found to be within $1 \mathrm{~mm}$ of the weld center, where the temperature is relatively uniform ${ }^{[5,6]}$. The consistency seen in the heating stage in Fig. 2 (a), where all the curves fully overlap, gives confidence in the repeatability of the measurements. The average peak temperatures were determined from three repeated tests.

As soon as welding was initiated, the temperature rose rapidly at a rate approaching $1000 \mathrm{Ks}^{-1}\left({ }^{\circ} \mathrm{C} \mathrm{s}^{-1}\right)$ for the first 0.4 seconds. For longer welding times, the temperature increased more slowly through the rest of the cycle as a steady state is approached. It can be seen that for welds with duration longer than 1 second the interface temperature exceeded $773 \mathrm{~K}\left(500^{\circ} \mathrm{C}\right)$. A similar rapid temperature rise has been measured using thin-film microsensors placed at the interface in USW of copper battery tabs by Zhao et al. ${ }^{[33]}$. After the power was turned off, the temperature initially dropped rapidly down to $573 \mathrm{~K}\left(300^{\circ} \mathrm{C}\right)$, before then decaying more gradually to room temperature. The two aluminum alloys used in the present study did not produce significantly different temperature histories, although there was a minor systematic difference in the peak weld temperatures. Welds produced under the same conditions with the 6111 alloy combination were consistently around $5-8 \mathrm{~K}\left({ }^{\circ} \mathrm{C}\right)$ hotter than for the AA7055-DC04 Steel samples (Fig. 2 (b)). 


\subsection{Weld Characterization}

Following welding, the interface between the aluminum and steel weld members was analyzed by electron microscopy at increasing resolution (Figs. 3, 5, 6). Fig. 3 shows macro views of typical cross sections of the joints made by USW, produced with the two material combinations for a weld time of 1.5 seconds. In the weld area, both parent metals were deformed by the sontrode tip teeth sinking into the sheet surfaces, and this macroscopic deformation was transmitted directly through the samples, resulting in a slightly wavy interface and local variation in the contact pressure ${ }^{[7]}$. Therefore, In order to take into account the effect of varying contact conditions along the join line, in all samples the IMC layer thickness was averaged over the central region shown by the black box in Fig. 3. It can be noted that for the AA7055 alloy the sheet appeared less deformed after welding, due to its higher hardness compared to AA6111, but the cross sections of both joints still have a similar overall profile.

\subsubsection{Analysis of the Joint Interfaces}

The development of the IMC interface reaction layer in each sample set was investigated by electron microscopy, as a function of welding time from 0.2 to 2.0 seconds. The average thicknesses of the IMC layers are plotted in Fig. 4 and typical images of the joint interfaces are shown in Figs. 5 -6. The interface layer developed similarly in both material combinations, although the kinetics were significantly more rapid in the case of the welds produced with the higher strength zinc containing AA7055 alloy, both during welding and in long term isothermal heat treatments applied after the samples were joined (Fig. 4 ). In the initial stage of welding $(<0.7 \mathrm{~s})$, individual IMC islands formed at the weld interface, with a thickness of less than $200 \mathrm{~nm}$. These small, discontinuous, IMC regions could only be reliably identified using TEM, and an example is shown in Fig. 5 (a) and (b). The IMC islands were $0.5-5 \mu \mathrm{m}$ wide and a single grain thick, with the grains themselves being elongated along the interface. As the welding time increased above 0.7 seconds, the IMC islands merged into an irregularly thick, continuous, layer. At the maximum welding time used of 2.4 seconds, the IMC layer had still only reached 2.0 and $2.5 \mu \mathrm{m}$ thick in the AA6111-DC04 and AA7055-D04 welds, respectively.

In the first stage of IMC development the intermetallic islands were identified in the TEM by selected area diffraction (SADP) to consist entirely of $\eta\left(\mathrm{Fe}_{2} \mathrm{Al}_{5}\right)$ phase (Fig. 5 (b)). In the second stage, the thicker continuous IMC layer that formed became identifiable in SEM images by its intermediate back scattered contrast relative to the parent materials (Fig. 5 (c) and (e)). At a higher resolution, for welding times greater 
than 1 second, a dual layer IMC structure was identified in both material combinations that consisted of continuous layers of $\theta\left(\mathrm{FeAl}_{3}\right)$ and $\eta\left(\mathrm{Fe}_{2} \mathrm{Al} \mathrm{I}_{5}\right)$ phase. These two distinct layers were indexed both by TEM SADP (Fig. 5 (c) and (e)) and high resolution EBSD (Fig. 6(a)). As expected ${ }^{[2-6]}$, the phase with the highest iron content $\left(\eta-\mathrm{Fe}_{2} \mathrm{Al}_{5}\right)$ was found to be located on the steel side, and that with the highest aluminum content $\left(\theta-\mathrm{FeAl}_{3}\right)$, on the aluminum side of the joint interface. In both sets of welds, as the reaction layer grew thicker, the two IMC phases developed a columnar grain structure (Fig. 6(a)) and, although there was strong local variation, the fraction of each phase present was approximately similar. Furthermore, the pole figures shown in Fig. 6 reveal that the $\eta$ phase developed a fiber texture with the [001] direction preferentially orientated in the direction of columnar growth (i.e. normal to the interface plane). The monoclinic $\theta-\mathrm{FeAl}_{3}$ phase also appeared to have a weak fiber texture, with its [010] direction aligned preferentially approximately normal to the joint interface (Fig. 6(c)), although because it is only possible to map small sections of interface it was difficult to obtain statistically valid data to confirm the texture strength.

In Fig. 7 results from EDX composition line-scans, obtained by TEM across the IMC interface layers, are shown after a weld time of 1.5 second. It can be seen that the measured Fe to Al ratios are consistent with the presence of two sub-layers of composition $\mathrm{FeAl}_{3}$, and $\mathrm{Fe}_{2} \mathrm{Al}_{5}$, as identified by SADP. However, more importantly, the EDX profiles show that in the AA7055- DC04 welds zinc was measured to be dissolved in both IMC phases at a concentration of approximately 1 - 2 at. \%. In contrast, no other alloying element was detected at a significant concentration within the intermetallic reaction layers in any of the welds; indicating that of the all the alloying elements present, only zinc had a significant solubility in the AI-Fe IMC phases.

When the welding time was increased above 1.5 seconds further differences were observed with respect to the two aluminum alloys used to produce the two sets of dissimilar welds (Fig. 8). In the AA6111-DC04 joints a large number of IMC particles were found embedded in the aluminum alloy matrix some distance from the weld interface. EDX point analysis revealed that the compositions of the iron rich particles were consistent with the presence of the $\theta\left(\mathrm{FeAl}_{3}\right)$ phase. This was also confirmed by EBSD phase identification mapping; as can be seen in Fig. 6(a).

In comparison in the AA7055 - DC04 joints, two additional features were found near the join line: namely voids that appeared in the aluminum matrix close to the IMC layer (Fig. 8 (b)) and local regions with eutectic rich, dendritic microstructures, which is indicative of partial melting occurring in the aluminum alloy near the weld interface (Fig. 8 (b)). These two types of feature were found only in the central region of 
each weld, where the highest peak temperatures were reached ${ }^{[5]}$. However, far fewer embedded $\mathrm{FeAl}_{3}$ particles were found in the aluminum matrix in the AA7055-DC04 welds and no evidence could be found for incipient melting occurring in the welds produced with the AA6111-DC04 material combination.

\subsubsection{Thermodynamic Modelling}

Ultrasonic welding is a very rapid process where kinetic considerations can potentially play a role in determining the IMC phases that form at the weld interface. Modelling was therefore used to see if the phases identified in the experimental results were consistent with those expected from their relative thermodynamic stability, within the material couples studied. Results from predictions made by the CALPHAD method, using CompuTherm LCC's Pandat ${ }^{\mathrm{TM}}$ software with the database PanAl2013, are provided in Fig. 9. Example isopleths are shown, as a function of iron content, calculated at close to the peak welding temperature of $773 \mathrm{~K}\left(500^{\circ} \mathrm{C}\right)$ for the binary Al-Fe system and compositions equivalent to when DC04 steel is welded to each of the AA6111 or AA7055 aluminum alloys investigated. Several important points emerge from these calculations. Firstly, the stable composition ranges of the Al-Fe IMC phases are not greatly influenced by the additional elements present in the alloys investigated, relative to those in the binary system. Secondly, although both $\theta$ and $\eta$ are predicted to be the thermodynamically stable in all cases (Figs. 9 (a), (b) and (c)), $\mathrm{FeAl}_{2}$ and FeAl are also expected as equilibrium phases around the composition ratios of 66:34 and 52:48 (Al: Fe at.), respectively. Thirdly, zinc is predicted to have a solubility larger than 10 wt. \% in the $\eta$ and $\theta$ phases according to the Fe-Al-Zn ternary phase diagram ${ }^{[19]}$ and when added to the binary AlFe system at the levels found in the AA7055 alloy ( 8 wt. \%), no ternary Al-Fe-Zn phases are predicted. Finally, in the calculation for the AA7055-DCO4 combination in the $773 \mathrm{~K}\left(500^{\circ} \mathrm{C}\right)$ section a liquid phase can be seen to appear and the incipient melting point in the AA7055 alloy is predicted to be as low as $760 \mathrm{~K}$ $\left(487^{\circ} \mathrm{C}\right)$.

\subsubsection{Lap Shear Testing}

Lap shear tensile testing was used to measure the weld's failure loads and failure energies, as a function of welding time, for the two material combinations studied. Prior to testing, the welds were aged to T6 
tempers to obtain maximum strength from the aluminum parent materials, so that the results would represent the worst case scenario, in terms of the stress experienced by the weld interface.

The failure load and fracture energies for the joints after ageing are shown in Fig. 10. As the welding time increased from $0.3 \mathrm{~s}$ to $1.5 \mathrm{~s}$, the failure load for the AA6111-DC04 joints rose from $2.4 \mathrm{kN}$ to a maximum level of $3.2 \mathrm{kN}$. Longer welding times resulted in a progressive reduction in failure load to just below $3 \mathrm{kN}$ for the longest time studied, of 2.4 seconds. The fracture energies for the AA6111-DC04 joints showed a similar pattern, peaking after a welding time of 1.5 seconds, before decreasing again at longer times. In comparison, the AA7055-DC04 joints showed a similar response, in terms of the optimum welding time, but the peak failure load was always approximately 5\% lower than for the AA6111-DC04 welds and the fracture energy was less than half that for the welds produced with the lower strength aluminum alloy.

Examples of fracture surfaces from the peak strength lap shear tests, produced with a welding time of 1.5 seconds, are shown in Fig. 11. The macroscopic images (Figs. 11 (a) - (d) and (g) - (i)) confirm that an interface, or near interface, failure occurred in all the welds produced with both material combinations. More detail of the fracture surfaces can be seen in the higher magnification SEM images from both the steel and aluminum sides of each joint shown in the accompanying figures. Example results of EDX composition point analysis of different areas of the fracture surfaces are also shown in Fig. 11 . With the AA6111-DCO4 joint fracture surfaces (Figs 11 (b), (c), (e), (f)) the different contrast and EDX analysis revealed the presence of two distinct regions on each surface. The majority of the steel and aluminum sheet surfaces had an iron/aluminum composition ratio of $75 / 25$, which suggests that the fracture occurred predominantly in the $\theta\left(\mathrm{FeAl}_{3}\right)$ intermetallic layer. However, a significant surface area of local patches of aluminum was also found on the steel fracture surface, (Fig. 11(b)), suggesting that thin pieces of aluminum had been pulled out of the aluminum sheet close to the interface. These regions clearly showed evidence of ductile failure and this was probably responsible for the higher fracture energy seen for this weld combination (Fig. 11(c)).

In contrast, the fracture surfaces of the AA7055-DC04 joints revealed an entirely brittle behavior (Fig. 11(g I)). With these welds no aluminum was found adhered to the steel fracture surfaces, which appeared to be entirely covered with an IMC layer of composition consistent with the $\theta$ phase, apart from a low fraction of lighter contrast areas that EDX analysis revealed to be exposed steel, suggesting that no bonding had taken 
place in such regions, or the IMC layer had been pulled off the steel surface. In comparison, in these welds few IMC areas could be detected on the fracture surface of the aluminum side of the joints, suggesting that failure occurred at the interface between $\theta\left(\mathrm{FeAl}_{3}\right)$ phase and stronger aluminum alloy (Fig. 11(k), (I)). Some areas were also detected with high zinc content, that may corresponded to the locally melted eutectic regions noted above.

\section{Discussion}

In USW welding high-strain local deformation first initiates from friction between the two sheet weld members at contacting asperities on their microscopically rough faying surfaces, under the action of the clamping force and high frequency vibration, which creates a cyclic shear displacement across the weld interface $^{[9]}$. Energy is initially dissipated by sliding friction, but galling and 'microwelding' rapidly occurs due to local breakdown of the oxide coating at abrading surface asperities, which allows metallic bonds to be formed between the two sheets. Energy is then dissipated at a greater rate by plastic deformation ${ }^{[9]}$, leading to a rapid temperature rise when a high power is used. Contact then spreads across the interface as the material softens with increasing temperature and deforms more easily under the applied pressure, so that the microwelds increase in density and expand across the interface as welding progresses ${ }^{[9]}$. However, because USW involves the progressive development and coalescence of microwelds, a small fraction of unwelded interface is usually left at the end of the process ${ }^{[9]}$. For example, in this work EDX analysis revealed small exposed patches of steel on the fracture surfaces of some of the welds, suggesting that some regions remained where no bonding had taken place. In similar welding, with increasing welding time, the interface also becomes displaced and convoluted by the extensive plastic flow that occurs ${ }^{[9,34]}$. In conventional, similar, USW the weld strength therefore increases with welding time as the density of microwelds increases, but also goes through an optimum because the joint strength is ultimately limited by nugget tear-out and with long welding times thinning of the weld area occurs as the sontrode tips progressively sink into the sheet surfaces when the temperature rises ${ }^{[9]}$.

When ultrasonic welding dissimilar materials with low and high melting point, like aluminum and steel, the aluminum alloy deforms predominantly in the welding process ${ }^{[5,6]}$ as it softens much more dramatically with increasing temperature, while the steel sheet remains relatively undeformed, leading to only a very low displacement of the weld interface ${ }^{[5,6]}$. In the first stage of welding microwelds are thus first formed 
when the oxide film breaks down locally by abrasion of asperities on the steel surface. Inter-diffusion of aluminum and iron will then occur, which can lead to the formation of intermetallic reaction products at the joint interface. The reaction layer would therefore be expected to develop simultaneously with the welding process and, despite being relatively thin compared to that seen in fusion welding, the brittle nature of the IMC layer that forms can still dominate the failure behavior seen in the lap shear tests.

With both material combinations studied the formation and subsequent growth of the intermetallic phases produced by the reaction between ferrite and aluminum at the joint interface behaved similarly. The IMC reaction itself can be divided into three stages. In the initial stage of welding $(<0.5 \mathrm{~s})$, isolated IMC islands were formed on the steel side of the interface (Fig. 5). This first stage occurred extremely rapidly when the temperature was still increasing (Fig. 2). In the next stage, lateral growth of the IMC islands took place until they merged to form a continuous layer with a thickness of around $0.4 \mu \mathrm{m}$. This occurred in the following 0.2-0.5 seconds of welding, where the temperatures approached a plateau value of around $500^{\circ} \mathrm{C}$. In the final stage, the now continuous IMC layer continued to grow into both metals, but more rapidly into the aluminum sheet, and a second intermetallic phase formed as a continuous sub-layer on the aluminum side of the joint, leading to the dual layer structure seen in the welds produced with the longest welding times. In addition, in the welds produced for longer times with the AA6111 material the thicker reaction layers became damaged by the USW process (Fig. 8(a)), resulting in the dispersal of IMC particles in the softer aluminum side of the joint, and in the welds made with the lower melting point AA7055 alloy the high interface temperatures reached $\left(>773 \mathrm{~K}\left(500^{\circ} \mathrm{C}\right) \mathrm{Fig} .2\right)$ caused some incipient melting at the joint interface.

\subsection{Development of the IMC layer at the joint interface}

In the early stage of joining discontinuous IMC islands were observed to form heterogeneously in local areas along the joint interface, and thus probably developed within the microweld regions that first formed when welding was initiated. The first intermetallic compound to nucleate within these reaction centers was identified to be $\eta\left(\mathrm{Fe}_{2} \mathrm{Al}_{5}\right)$ phase (Fig. 5(b)). As welding continued, the growing density of microwelds expanded the area of metallurgical contact and this would contribute to a more uniform development of reaction islands over the whole weld region. When combined with lateral spreading of the reaction centers, this would quickly lead to the development of a continuous IMC layer at the weld interface (Fig. 5(c)). 
Lateral growth of the IMC islands along the joint interface would also be facilitated by interfacial diffusion and the high strain rate deformation experienced by the aluminum alloy under USW conditions that has been shown to increase its vacancy concentration ${ }^{[5,6]}$.

Once the IMC islands merged, and a continuous reaction layer had formed, TEM and EBSD investigation revealed the development of a second IMC layer consisting of $\theta\left(\mathrm{FeAl}_{3}\right)$ phase on the aluminum side of the joint (Fig. 5(d, f), Fig 6(a)). For both material combinations, these two phases were the only intermetallic compounds detected, which is consistent with previous studies of Al-Fe weld couples ${ }^{[2-6,12-16]}$. CLPHAD calculations (Fig. 9) showed that these compounds are the most stable phases predicted within the composition ratios (at.) of $\mathrm{Al}$ to Fe of $71: 29$ to $74: 26$ and 75:25 to $78: 22$, for $\eta$ and $\theta$ respectively, but they are not the only stable IMCs in the Al-Fe system. At the weld temperature the $\mathrm{FeAl}_{2}$ and FeAl phases were also predicted to be stable around the (atomic) composition ratios of Al to Fe of $66: 34$ and 52:48, respectively. However, these phases have only been previously observed in dissimilar Al-steel diffusion couples after long term heat treatments ${ }^{[31]}$, so it can be concluded that they did not form under the rapid USW conditions used in the present work for kinetic reasons.

The observation that $\eta$ is normally the first phase seen to nucleate in Al-steel dissimilar welds is probably partly because aluminum has a higher diffusion rate in $\mathrm{Fe}$ than $\mathrm{Fe}$ in $\mathrm{Al}$, leading to ferrite at the contact surface becoming more rapidly supersaturated in aluminum, than the aluminum in iron, which would favor a phase first forming that has a higher Fe to Al ratio. However, it has also been suggested that this maybe because $\eta$ has a crystallographic habit orientation with ferrite ${ }^{[4]}$ which would favor a lower activation energy for nucleation. It has also been proposed that more rapid growth of $\eta$ can occur because it has a high density of vacant sites within its crystal structure along [001] c-axis ([001] direction) ${ }^{[4]}$, which would become particularly important when it forms a continuous layer across the interface as it will then effectively act as a diffusion barrier. The present work also shows that the $\eta$ phase grew with its [001] direction preferentially aligned normal to the interface, as has been previously reported ${ }^{[4,12,16]}$, which is parallel to the diffusion flux across the interface layer. The EBSD data also suggested that the $\theta$ phase had a preferred orientation normal to the interface, although to our knowledge this has not been previously reported (Fig. $6(\mathrm{~b}, \mathrm{c})$ ). The fact that both the $\eta$ and $\theta$ phases formed a fine columnar grain structure (Fig. 6(a)) will also further increase the flux of atoms through the IMC layer by grain boundary diffusion ${ }^{[20,24]}$. 
As a continuous IMC phase thickens, the concentration gradients driving diffusion through the layer will reduce and at some critical point it will become more favorable for a phase with a different stoichiometry to nucleate ${ }^{[20-23]}$. The next phase observed to develop was $\theta\left(\mathrm{FeAl}_{3}\right)$, which formed on the aluminum side of the joint in both material combinations, owing to its higher aluminum to iron ratio. This phase has also been observed in other studies on dissimilar welding of aluminum and steel ${ }^{[20]}$.

In the AA7055-DC04 combination the base aluminum alloy had a relatively high zinc content of 8 wt\%. Consistent with our observations, thermodynamic modelling has shown that no ternary Al-Fe-Zn compounds are expected at this zinc level, although zinc was detected by EDX in the TEM to dissolve into the $\eta$ and $\theta$ phases at a similar level of 1-2 at. \% (Fig. 7(c)). A range of ternary phases can form at higher zinc ratios, but these are predicted to be well outside of the range of the zinc level present in a conventional aluminum alloy ${ }^{[27]}$. The average IMC layer thickness was, however, observed to be thicker in the welds produced with the zinc-containing AA7055 aluminum alloy (Fig. 4a). Although the differences in peak temperatures reached between these two sets of welds was very small $(<1 \%)$, due to uncertainty in the temperature measurements and damage to the IMC layer disproportionally affecting the layer thickness in the case of the AA6111 and DC04 welds, long duration isothermal treatments at $723 \mathrm{~K}\left(450^{\circ} \mathrm{C}\right)$ were also performed on samples pre-welded for 1 second. These results are given in Figure 4(b) and clearly show that under more controllable conditions the IMC layer thickened at approximately twice the rate in the zinc containing AA7055 - DC04 weld combination, relative to in the zinc free AA6111 and DC04 welds. It is therefore likely that the small concentration of zinc dissolved into the IMC phases is linked to this increased growth rate, but the exact mechanism still requires further investigation.

When the AA6111 and DC04 sheets were welded for longer than 1.5 seconds a large number of small fragments of $\theta$ phase were found distributed in the aluminum alloy near the interface. The high cooling rates in the welding cycle suggests that it is unlikely that these particles could have formed by precipitation. This behavior can therefore be attributed to the high frequency cyclic shear that is imposed across the weld interface in USW, which damaged the outermost IMC layer as it grew into the aluminum material near the weld interface ${ }^{[7-9]}$. In high power ultrasonic spot welding of dissimilar metals, material flow and extensive deformation is known to occur in the softer weld member within a highly deformed layer near the weld line ${ }^{[5,6]}$. This intense deformation would have fractured IMC grains that protrude ahead of the transformation 
front and incorporated the debris in to the aluminum sheet. As few IMC particles were found in the AA7055-DC04 joints, this suggests that less damage occurred to the reaction layer in this weld couple.

This difference in damage to the IMC layers seen in the two sets of materials can be related to the observation of local melting in the AA7055-DC04 welds, which will limit shear transfer at the join line and thus reduce fracture of IMC grains growing in the reaction layer. The melting point of the AA7055 alloy was predicted to be about $760 \mathrm{~K}\left(487^{\circ} \mathrm{C}\right)$. Thermocouple measurements have shown that at the weld center this temperature was exceeded within a welding time of 1 second and reached nearly $803 \mathrm{~K}\left(530^{\circ} \mathrm{C}\right)$ after a welding time of 2 seconds. The presence of a liquid phase could also have significantly affected the IMC growth rate in the AA7055-DC04 welds at long weld durations.

\subsection{Relationship between interfacial microstructure and mechanical properties of the joints}

Without achieving a high energy nugget pull-out fracture behavior a spot weld will not be fit for purpose in a safety critical application. Form the above discussion, it is apparent that when ultrasonic welding dissimilar metals, that can form IMCs by inter-diffusion and metallurgical reaction, there is competition between the formation and spread of microwelds across the joint interface, which increases the bond strength, and the coalescence and thickening of the IMC reaction layer, which will encourage a brittle interface failure ${ }^{[5,6]}$.

Unfortunately, in the welds produced in this study failure always occurred close to, or through, the weld interface. Previously it has been found that when ultrasonic spot welding medium strength aluminum alloys, like AA6111 to steel sheet, with the same welding set-up to that used here, it was possible to obtain pullout failures under optimum welding conditions ${ }^{[5,6]}$. However, in this work the welds were shear tested with the aluminum sheet in a weaker T4 temper condition and lower weld strengths $(2.8 \mathrm{kN})$, were achieved than have been obtained in the present study. In this prior investigation ${ }^{[6]}$ it was also found that the failure process reverted to interface failure at longer welding times when the IMC layer became thicker. Surprisingly, the weld failure energies for the optimum (pull-out) condition in this earlier work were only $25 \%$

greater $\left(\sim 4 \mathrm{kN} \cdot \mathrm{mm}{ }^{[6]}\right)$ than those measured for the AA6111-DC04 welds in the current investigation, and this reflects the lower strength condition of the aluminum sheet used previously, as well as the fact that (as 
will be discussed below) the failure process seen here in this material combination was not purely through the brittle IMC layer.

When measured after ageing the aluminum alloys to stronger T6 tempers, in the present study, the welds showed failure loads of over $3 \mathrm{kN}$ at an optimum time of 1.5 seconds (Fig. 10). In comparison, the highest fracture energy obtained for the AA6111-DC04 combination was $3.2 \mathrm{kN} . \mathrm{mm}$, whereas for the AA7055-DC04 welds it was only $1.7 \mathrm{kN} . \mathrm{mm}$. For the AA6111-DC04 welds this is about $40 \%$ of that measured for the equivalent similar aluminum-aluminum welds, which exhibit nugget pull-out by the more energy intensive process of ductile tearing ${ }^{[6]}$.

The lower failure energies seen in the present study, and in particular with the AA7055-DC04 welds, are due to crack propagation occurring predominantly through the brittle IMC layer at the weld interface. It should be noted that in the prior study, which tested the AA6111 alloy in a weaker T4 condition, fracture also occurred along the interface in the IMC layer when it grew thicker at longer welding times ${ }^{[6]}$. The higher strength of the aluminum materials tested here has therefore had the effect of tipping the balance back in favor of interface failure, owing to the higher loads that are transmitted across the joints before yielding occurs. In the present work fractography (Fig. 11) suggests that fracture occurred mainly through the IMC layer, or at the interface between $\theta$ phase and aluminum matrix. There was thus a tendency for the weld strength to decrease with longer welding times when the IMC layer became thicker $[5,6]$.

In the fractured AA6111-DC04 samples a significant total area of patches of aluminum were, however, found adhered to the steel sheet, which in places covered up to $45 \%$ of the fracture surface. At these locations the fracture surfaces showed evidence of the ductile tearing out of thin pieces of aluminum from near the join line. This behavior was probably encouraged by the high density of brittle $\theta$ phase particles embedded in the AA6111 side of the joint, due to the partial break-up of the IMC layer in these samples. The height of the adhered aluminum patches $(\sim 7 \mu \mathrm{m})$ was measured to be similar to the depth the brittle $\theta$ phase particles were embedded within the aluminum sheet when the IMC layer partially broke up during the welding process (Fig. 8(a)), confirming this view. This mixed fracture behavior was thus responsible for the surprisingly high failure energies seen for the AA6111-DC04 welds, despite the fracture path following quite close to the weld interface. 
In contrast, despite being produced with a much stronger parent material, the AA7055-DC04 welds showed a slightly lower strength in the lap shear tests and a much lower fracture energy of less than half that of the AA6111-DC04 samples. This difference is clearly associated with the more brittle interface fracture seen in the AA7055-DC04 weld samples, when lap shear tested (Fig. 11) which is partly related to the thicker reaction layer found in this system. However, the stronger AA7055 aluminum sheet would also transmit a higher load to the joint interface. In addition, with the AA6111-DC04 samples the weaker outer layer $\theta$ IMC grains, that were more prone to fracture/debonding in the AA7055-DC04 welds, were already selectively dispersed into the aluminum matrix by the greater damage induced to the IMC layer by the USW welding process. For the AA7055-DC04 welds, it is also likely that the local melting behavior and associated porosity seen at the join line reduced the interface strength.

\section{Summary and Conclusions}

The present study has investigated the influence on weld performance of the formation and growth stages of the intermetallic compounds (IMCs) formed at the interface in joints produced between a DC04 steel and two different aluminum alloys (AA6111 and AA7055) by high power ultrasonic spot welding (USW).

By optimizing the welding time, attractive joint strengths could be achieved by USW. However, no suitable process window was found that could produce welds with a nugget pullout failure mode, using the current welding procedure. In all cases the fracture path was through the weld interface region. A purely brittle fracture, at the interface between the aluminum alloy and the IMC reaction layer, was seen in the AA7055DC04 welds, whereas a higher energy mixed mode failure was found in the AA6111-DC04 combination.

In the high power USW process studied the temperature was found to rise rapidly, reaching $500^{\circ} \mathrm{C}$ within 1 second, which encouraged IMC formation and led to incipient melting at the weld interface with the AA7055 alloy.

In both material combinations a similar sequence of Intermetallic compound formation was observed during the welding cycle. $\eta-\mathrm{Fe}_{2} \mathrm{Al}_{5}$ was found to be the first IMC phase to nucleate, within a welding time of only 0.3 seconds, as isolated islands heterogeneously distributed at the weld interface. These early reaction centers formed within the microweld regions that first develop at initial asperity contact points across the joint interface. The IMC islands then spread to form a continuous layer in both material combinations, by a 
welding time of 0.7 seconds. With longer welding times a second IMC phase, $\theta-\mathrm{FeAl}_{3}$, was seen to develop on the aluminum side of the joints.

The reaction layer in the AA7055-DC04 welds was found to grow thicker than in the AA6111-DC04 samples in both as-welded and as-annealed states and this may be related to the dissolution of zinc into the IMC layer. Thermodynamic modelling showed that no zinc containing IMC compounds are expected in the welds produced with the AA7055 alloy.

\section{Acknowledgements}

This work was funded by the EPSRC throughLATEST2, Light Alloys towards Environmentally Sustainable Transport (EP/H020047/1). The authors acknowledge the China Scholarship Council (CSC, 2011612008) for financial support and would like to thank Novelis UK and Airbus UK for the provision of materials.

\section{References}

[1] H. Chen, A. J. Pinkerton, L. Li, Z. Liu, A. T. Mistry: Mater. Des., 2011, vol. 32, pp. 495-504.

[2] R. Qiu, C. Iwamoto, S. Satonaka: J. Mater. Process. Technol., 2009, vol. 209, pp. 4186-93.

[3] G. Sierra, P. Peyre, F. Deschaux-Beaume, D. Stuart, G. Fras: Mater. Sci. Eng. A, 2007, vol. 447, pp. 197208.

[4] H. Springer, A. Kostka, E.J. Payton, D. Raabe, A. Kaysser-Pyzalla, G. Eggeler: Acta Mater., 2011, vol. 59, p. 1586-1600.

[5] F. Haddadi, D. Strong and P. B. Prangnell. JOM, 2012, vol. 64, pp. 407-413.

[6] F. Haddadi, Y-C. Chen, P.B. Prangnell: Mater. Sci. Technol., 2011, vol. 27, pp. 617-624.

[7] V.K. Patel, S.D. Bhole, and D.L. Chen: Metall. Mater. Trans. A, 2014, vol. 45A, pp. 2055-2066.

[8] T. Watanabe, H. Sakuyama, A. Yanagisawa: J. Mater. Process. Technol., 2009, vol. 209, pp. 5475-80. 
[9] D. Bakavos, P.B. Prangnell: Mater. Sci. Eng. A, 2010, vol. 527, pp. 6320-34.

[10] Y. Chen, A. Gholinia, P.B. Prangnell: Mater. Chem. Phys., 2012, vol. 134, pp. 459-463.

[11] W. Cheng, C. Wang: Appl. Surf. Sci., 2011, vol. 257, pp. 4663-4668.

[12] M. Eggersmann, H. Mehrer: Philos. Mag. A, 2000, vol. 80, pp. 1219-44.

[13] S. Hirose, T. Itoh, M. Makita, S. Fujii, S. Arai, K. Sasaki, H. Saka: Intermetallics, 2003, vol. 11, pp. 633-642.

[14] N. Tang, Y.P. Li, S. Kurosu, Y. Koizumi, H. Matsumoto, A. Chiba: Corros. Sci., 2012, vol. 60, pp. 32-37.

[15] W. Lee, M. Schmuecker, U. A. Mercardo, G. Biallas, S. Jung: Scr. Mater., 2006, vol. 55, pp. 355-358.

[16] C. Rest, P.J. Jacques, A. Simar: Scr. Mater., 2014, vol. 77, pp.25-28.

[17] Q. Wang, X. Leng, T. Yang, J. Yan: Trans. Nonferrous Met. Soc. China, 2014, vol. 24, pp. 279-284.

[18] M. Yan, Z. Fan: J. Mater. Sci., 2000, vol. 35, pp. 1661-67.

[19] V. N. Yeremenko, Y. V. Natanzon and V. I. Dybkov: J. Mater. Sci., 1981, vol. 16, pp. 1748-56.

[20] K. Bouché, F. Barbier, A. Coulet: Mater. Sci. Eng. A, 1998, vol. 249, pp. 167-175.

[21] H.R. Shahverdi, M.R. Ghomashchi, S. Shabestari, J. Hejazi: J. Mater. Process. Technol., 2002, vol. 124, pp. $345-352$.

[22] A. Bouayad, Ch. Geromett, A. Belkebir, A. Ambari: Mater. Sci. Eng. A, 2003, vol. 363, pp. 53-61.

[23] S. Bozzi, A.L. Helbert-Etter, T. Baudin, B. Criqui, J.G. Kerbiguet: Mater. Sci. Eng. A, 2010, vol. 527, pp. 4505-09.

[24] D. Naoi, M. Kajihara: Mater. Sci. Eng. A, 2007, vol. 459, pp. 375-382.

[25] K. Wang, L. Chang, D. Gan, H. Wang: Thin Solid Films, 2010, vol. 518, pp. 1935-42.

[26] H. Springer, A. Kostka, J.F. dos Santos, D. Raabe: Mater. Sci. Eng. A, 2011, vol. 528, pp. 4630-42.

[27] A.R. Marder: Prog. Mater. Sci., 2000, vol. 45, pp. 191-271.

[28] S. Liu, C. Li, S. Han, Y. deng, X. Zhang: J. Alloys Compd., 2015, vol. 625, pp. 34-43. 
[29] H. Yu, M. Wang, X. Sheng: J. Alloys Compd., 2013, vol. 578, pp. 208-214.

[30] G. Stechaunera, E. Kozeschnikb.: Calphad, 2014, vol. 47, pp. 92-99.

[31] R. K. W. Marceau, A. de Vaucorbeil, G. Sha, S.P. Ringer, W. J. Poole: Acta Mater., 2013, vol. 61, pp. 7085-7303.

[32] J. M. Schreiber, Z. R. Omcikus, T. J. Eden, M.M. Sharma, V. Champagne, S.N. Patankar: J. Alloys Compd., 2014, vol. 617, pp. 135-139.

[33] J. Zhao, H. Li, H. Choi, W. Cai, J.A. Abell, and X. Li: SME J Manu. Proc., 2013, vol. 15, pp. 136-140.

[34] S.S. Lee, T.H. Kim, S.J. Hu, W. Cai, J.A. Abell, and J. Li, ASME J Manu. Sci. \& Eng., 2013, vol 135(2).

\section{Figure Captions}

Fig. 1 The welding setup used in the current work; (a) schematic diagram of the ultrasonic welding machine, (b) the sonotrode tips and (c) an illustration of the weld coupon and position of the embedded thermocouple used for temperature measurement.

Fig. 2 Results from thermal measurements made at the weld interface: (a) example temperature histories from AA7055- DC04 welds, and (b) the peak temperatures reached when welding both material combinations, as a function of welding time.

Fig. 3 Examples of weld cross sections for the two material combinations for a weld time of 1.5 seconds (SEM montage); (a) AA6111 aluminium - DC04 steel, (b) AA7055 aluminium - DC04 steel. The box in each image designates the area used for measuring the IMC reaction layer thickness.

Fig. 4 Average total thickness of the IMC layer found at the weld interface, for both material combinations, as a function of (a) welding time and (b) on extended annealing at $723 \mathrm{~K}\left(450^{\circ} \mathrm{C}\right)$ of lightly pre-welded samples.

Fig. 5 SEM (left) and TEM (right) images of the IMC reaction layers seen in the AA6111- DC04 steel welds (a) and (b) after a short $0.3 \mathrm{~s}$, and (c) and (d) medium $1.5 \mathrm{~s}$ welding times. In (e) and (f) a comparison is 
provided to the equivalent AA7055- DC04 steel welds after a welding time of $1.5 \mathrm{~s}$. In the TEM images the dashed lines indicate the interfaces between the different phases. The solid lines indicate the position used for the composition line-scans shown in Fig. 7.

Fig. 6 (a) EBSD phase map of the dual phase IMC reaction layer seen in the AA6111-DC04 sample, after a welding time of 1.5 seconds. Note; the columnar grain structures of the IMC phases and small FeAl ${ }_{3}$ particles (red) embedded in the aluminium matrix away from the interface. In (b) and (c) pole figures are shown from the $\eta$ and $\theta$ phases, respectively, where ND is normal to the interface plane.

Fig. 7 Results from EDX composition line-scans obtained by TEM across the IMC interface layers for; (a) the AA6111-DC04 steel and (b) the AA7055-DC04 steel joints after a welding time of $1.5 \mathrm{~s}$. (c) Highlights the concentration of additional alloy elements (without Fe and Al) in the AA7055-DC04 joint using an expanded scale. The vertical dashed lines are the interface positions between different phases as obtained from the TEM images (Fig. 5).

Fig. 8 Interface region microstructures observed at longer welding times for both material combinations; (a) AA6111-DC04 joints with a welding time of 2 seconds and the AA7055-DC04 material combination with welding times of (b) 1.5 and (c) 2 seconds. Examples from EDX point analysis results are provided at the positions indicated (refer to key in each image).

Fig. 9 CALPHAD predicted equilibrium phase fractions as a function of Fe content at $773 \mathrm{~K}\left(500^{\circ} \mathrm{C}\right)$ for; (a) pure iron and aluminum, (b) AA7055-DC04 and (c) AA6111-DC04 steel.

Fig. 10 Average (a) Failure loads and (b) fracture energies obtained from lap shear tests conducted on welds produced with both material combinations, as a function of welding time.

Fig. 11 Fracture surfaces of the peak lap shear strength samples (1.5 second welding time) showing; macroimages (a), (d) and (g), (j) of the steel and aluminum surfaces for the DC04-AA6111 and DC04-AA7055 weld combinations, respectively, with accompanying higher magnification SEM images from the regions highlighted in the macro-images of the steel side, (b) (c), (h) and (i), and the aluminium side of each joint in (e), (f), (k) and (I). Examples of the local composition of specific regions determined by EDX point analysis are indicated (refer to key in each image). 
Table 1 Nominal chemical compositions (wt. \%) of the materials.

Table 2 Welding parameters used in the USW process. 
Table 1 Nominal chemical compositions (wt. \%) of the materials.

\begin{tabular}{llllllllll}
\hline \multirow{2}{*}{ Material } & \multicolumn{2}{l}{ Chemical compositions (wt. \%) } \\
\cline { 2 - 9 } & $\mathrm{Al}$ & $\mathrm{Fe}$ & $\mathrm{Mg}$ & $\mathrm{Mn}$ & $\mathrm{Si}$ & $\mathrm{Cu}$ & $\mathrm{S}$ & $\mathrm{C}$ & $\mathrm{Zn}$ \\
\hline 6111-T4 & balance & 0.26 & 0.58 & 0.20 & 0.82 & 0.59 & - & - & - \\
7055-T4 & balance & 0.1 & 2.3 & 0.05 & 0.1 & 2.0 & & & 8.4 \\
DC04 & 0.025 & balance & - & 0.40 & - & - & 0.03 & 0.08 & \\
\hline
\end{tabular}

Table 2 Welding parameters used in the USW process.

\begin{tabular}{cccc}
\hline Welding power $(\mathrm{W})$ & Impedance $(\Omega)$ & Pressure $(\mathrm{kN})$ & Welding time $(\mathrm{s})$ \\
\hline 2500 & 2 & 1.4 & $0.2-2.0$ \\
\hline
\end{tabular}


(a)

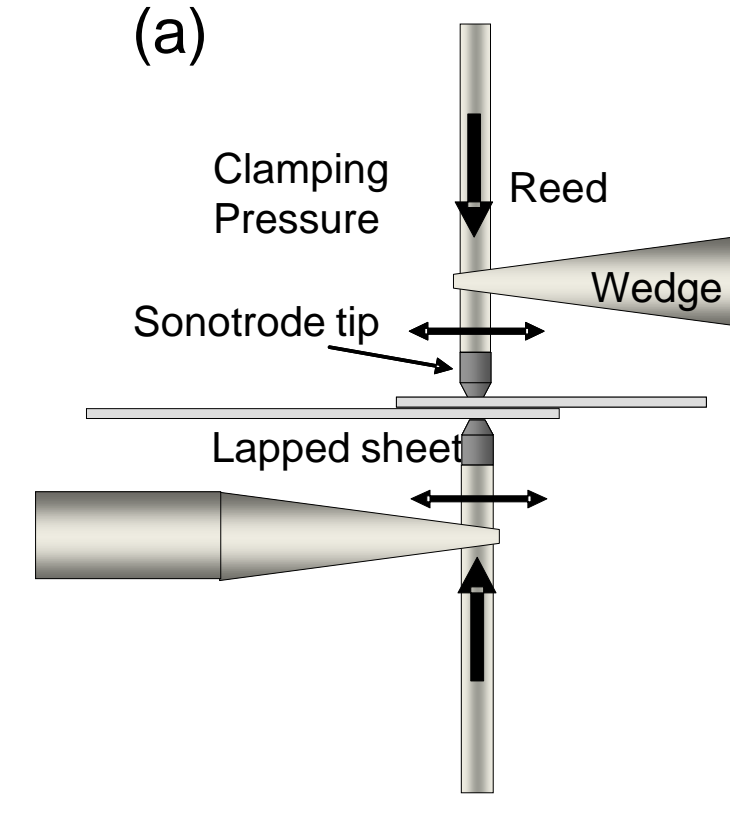

Steel Tip

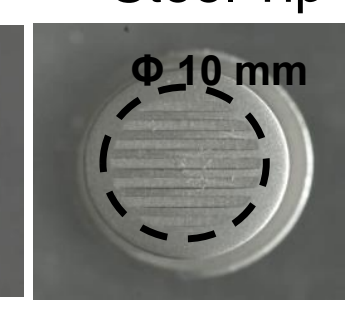

(c)

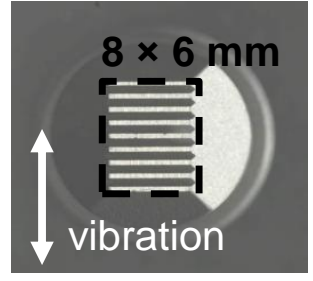

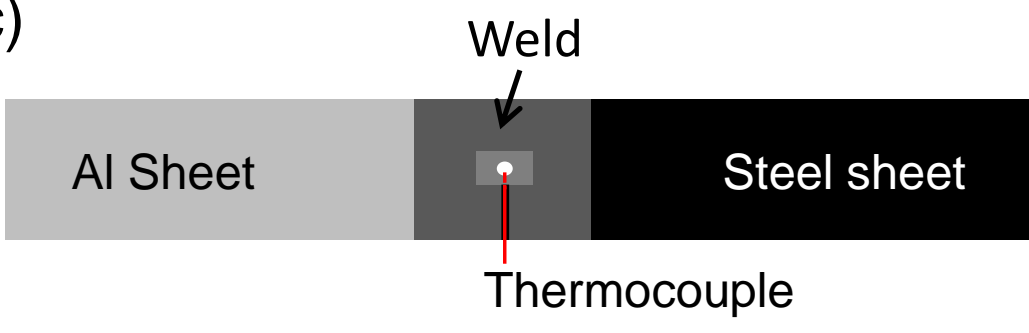

Fig. 1 The welding setup used in the current work; (a) schematic diagram of the ultrasonic welding machine, (b) the sonotrode tips and (c) an illustration of the weld coupon and position of the embedded thermocouple used for temperature measurement. 

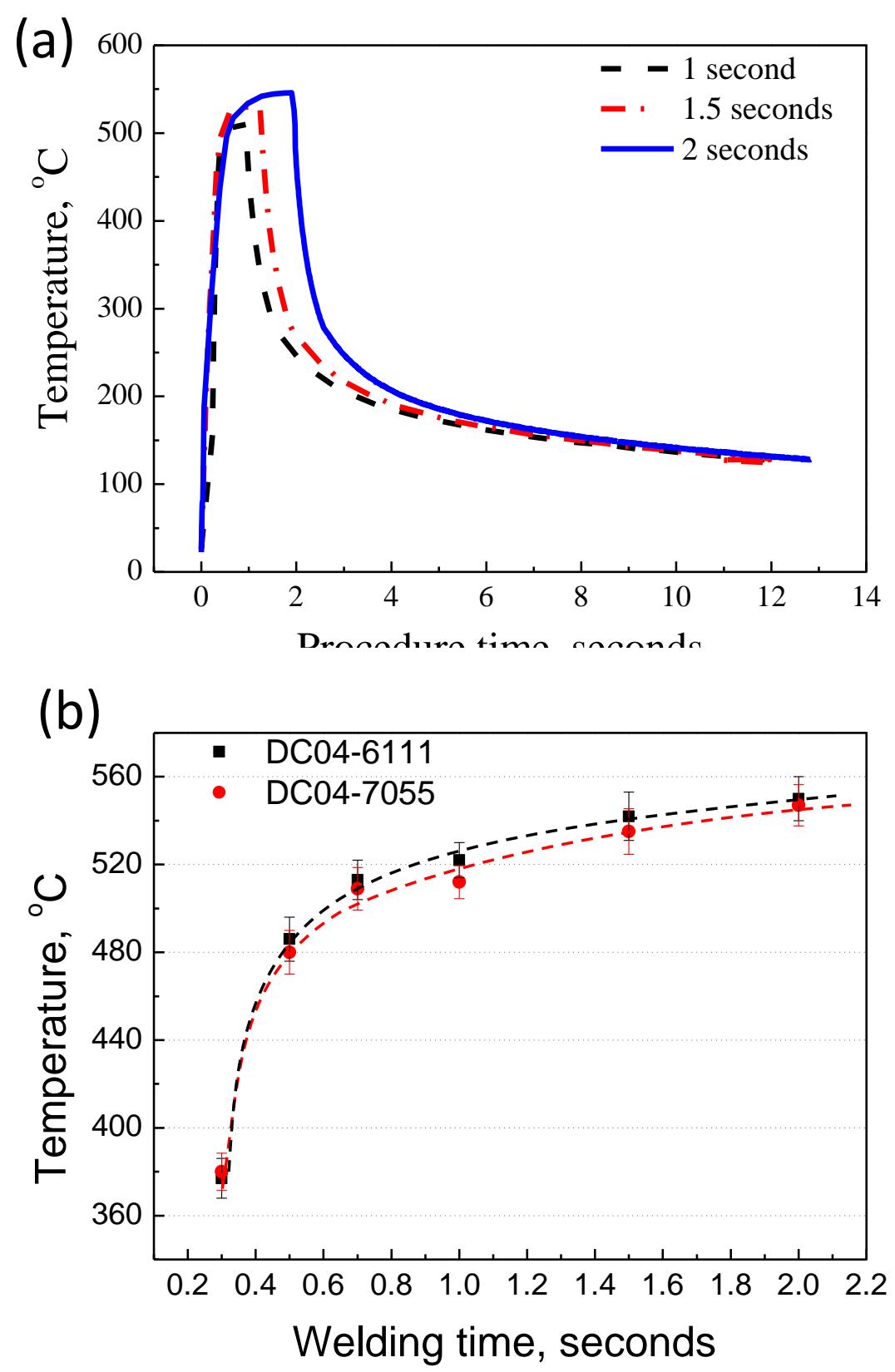

Fig. 2 Results from thermal measurements made at the weld interface: (a) example temperature histories from AA7055- DC04 welds, and (b) the peak temperatures reached when welding both material combinations, as a function of welding time. 

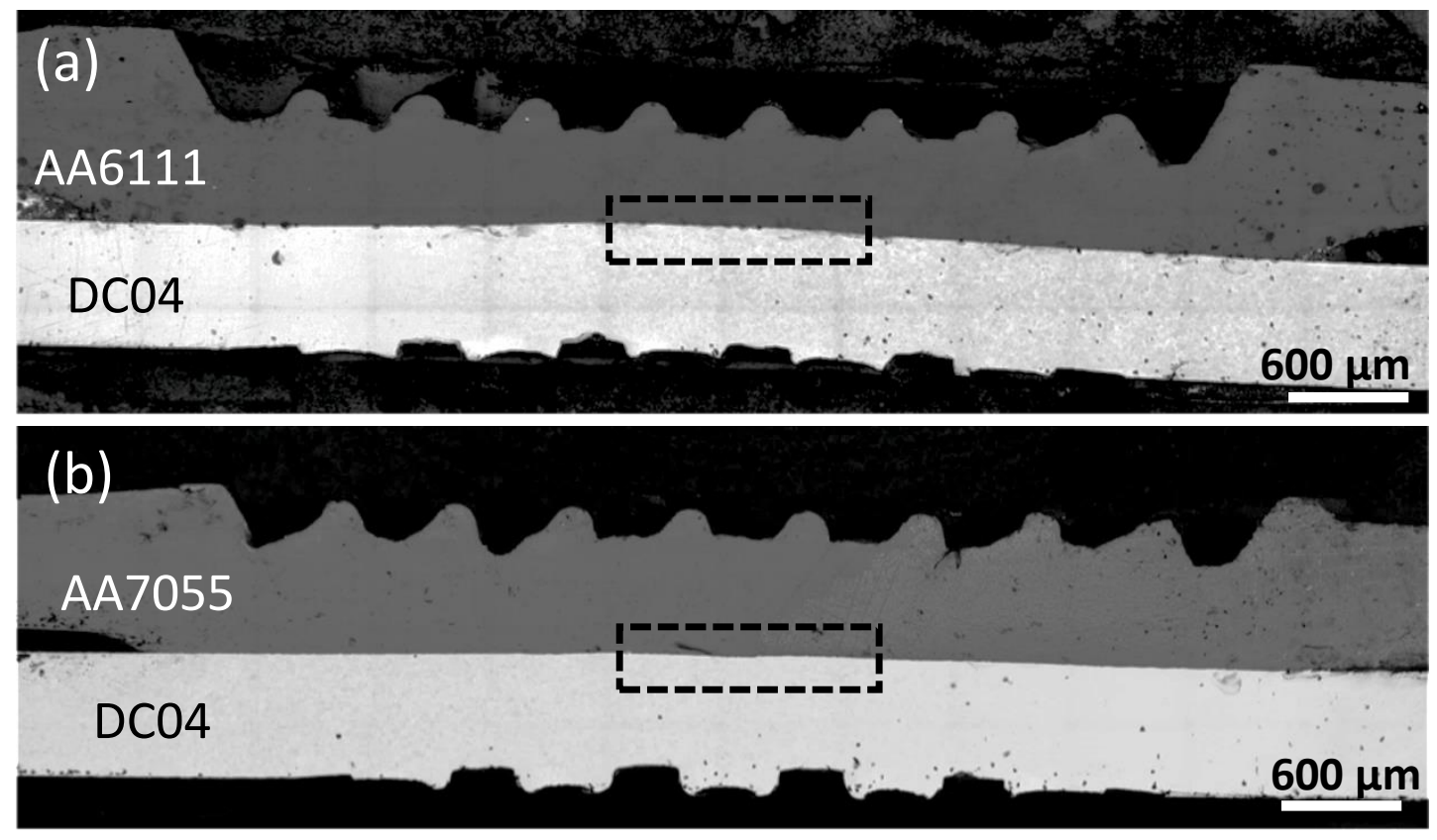

Fig. 3 Examples of weld cross sections for the two material combinations for a weld time of 1.5 seconds (SEM montage); (a) AA6111 aluminium DC04 steel, (b) AA7055 aluminium - DC04 steel. The box in each image designates the area used for measuring the IMC reaction layer thickness. 

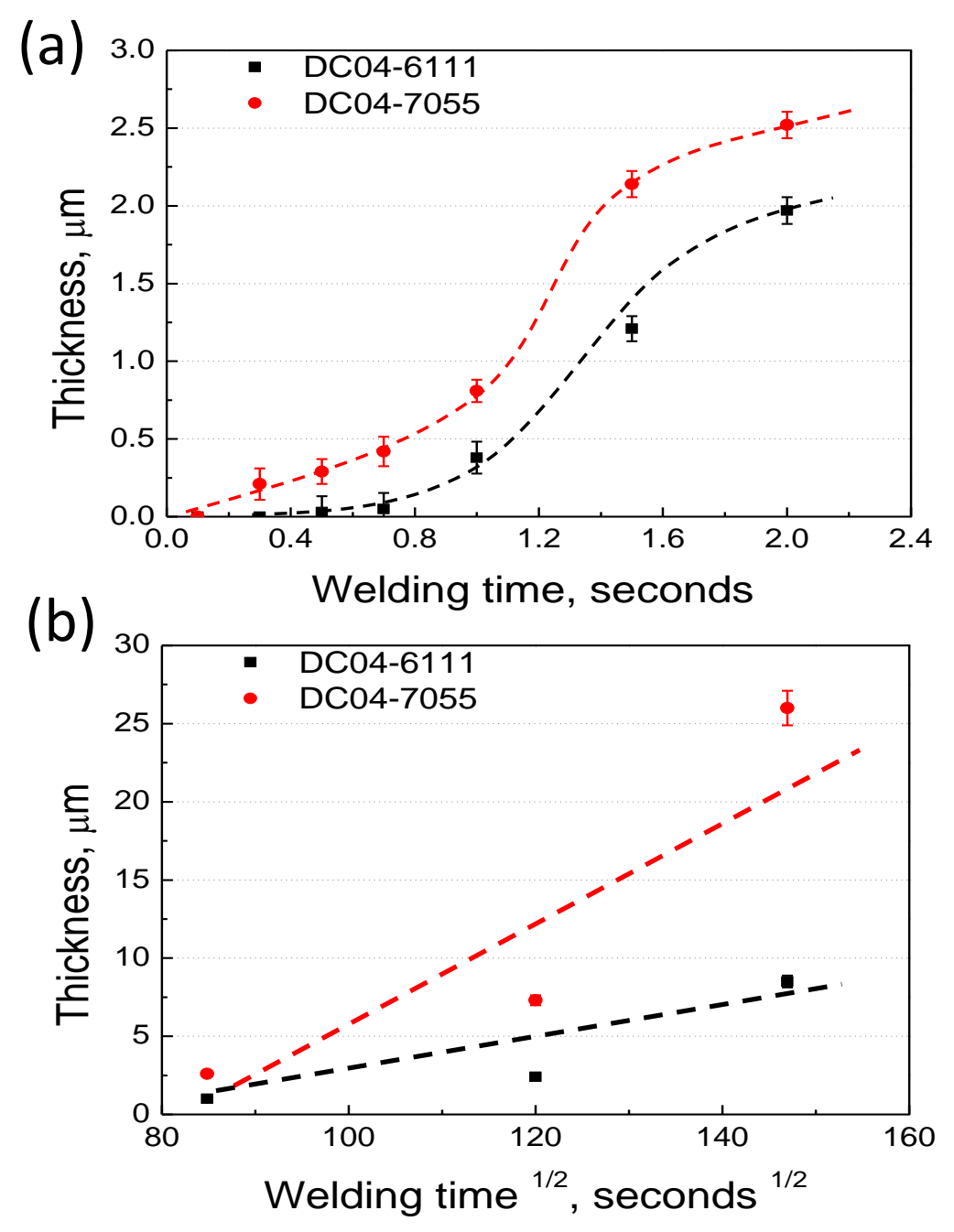

Fig. 4 Average total thickness of the IMC layer found at the weld interface, for both material combinations, as a function of (a) welding time and (b) on extended annealing at $450^{\circ} \mathrm{C}$ of lightly pre-welded samples. 


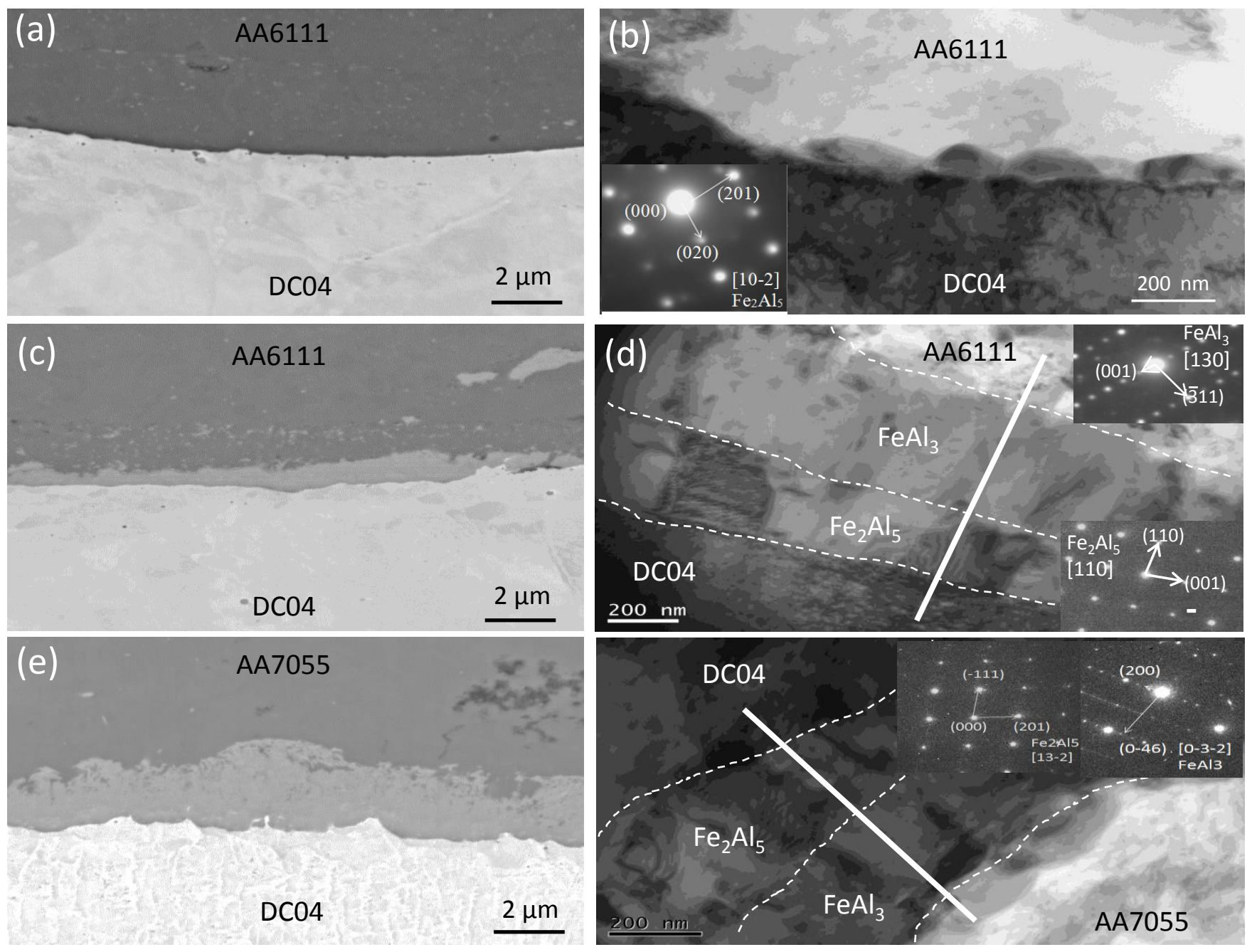

Fig. 5 SEM (left) and TEM (right) images of the IMC reaction layers seen in the AA6111- DC04 steel welds (a) and (b) after a short $0.3 \mathrm{~s}$, and (c) and (d) medium $1.5 \mathrm{~s}$ welding times. In (e) and ( $f$ ) a comparison is provided to the equivalent AA7055- DC04 steel welds after a welding time of $1.5 \mathrm{~s}$. In the TEM images the dashed lines indicate the interfaces between the different phases. The solid lines indicate the position used for the composition linescans shown in Fig. 7. 
(a)
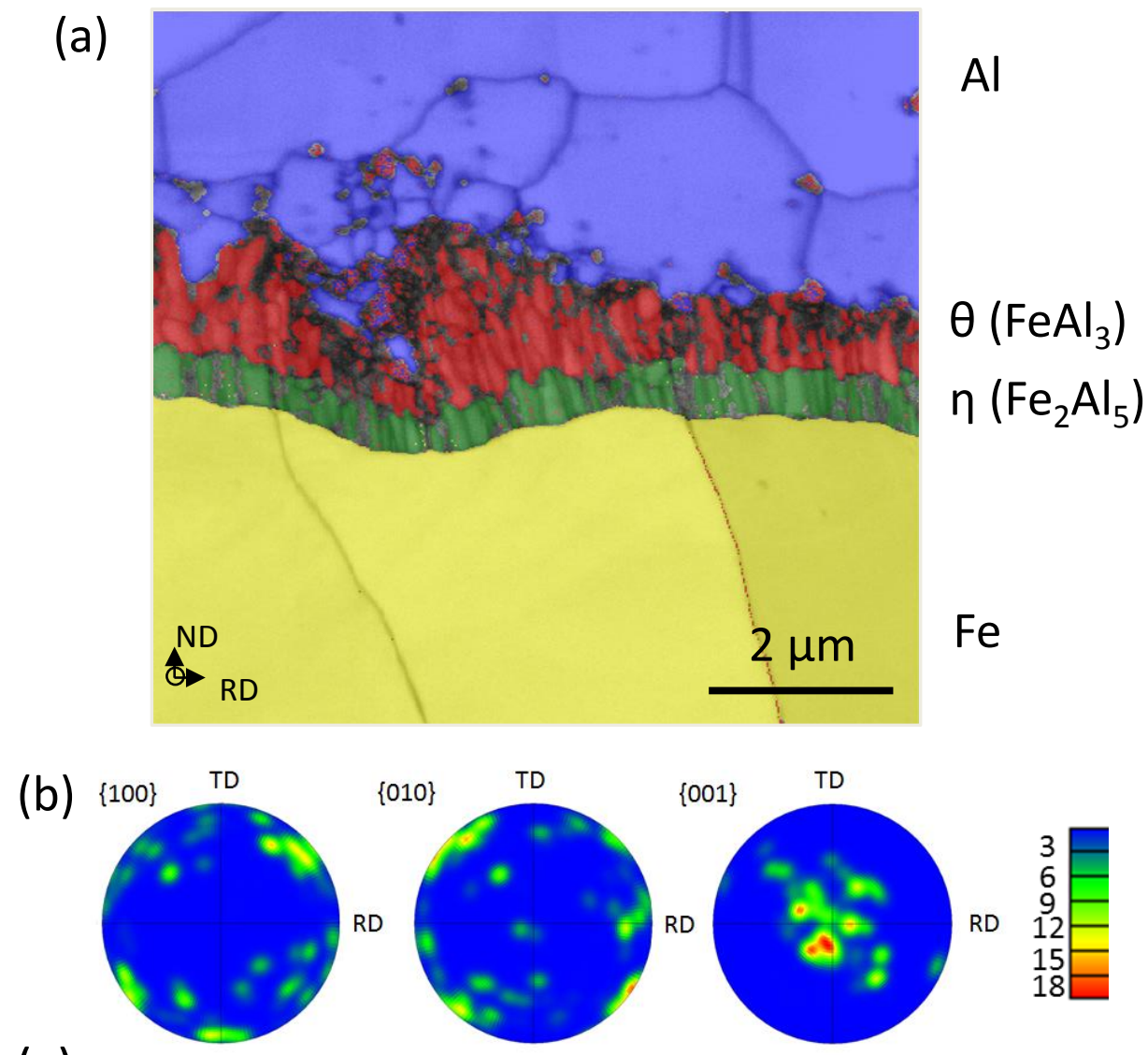

(c)

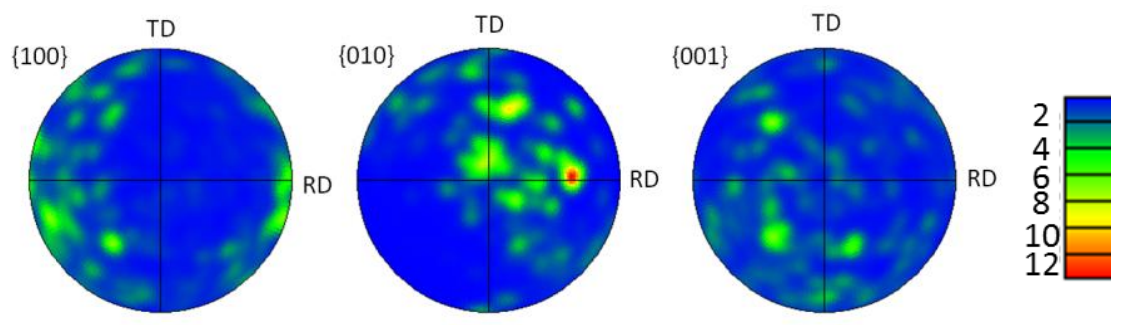

Fig. 6 (a) EBSD phase map of the dual phase IMC reaction layer seen in the AA6111-DC04 sample, after a welding time of 1.5 seconds. Note; the columnar grain structures of the IMC phases and small FeAl ${ }_{3}$ particles (red) embedded in the aluminium matrix away from the interface. $\ln (b)$ and (c) pole figures are shown from the $\eta$ and $\theta$ phases, respectively, where ND is normal to the interface plane. 
(a)

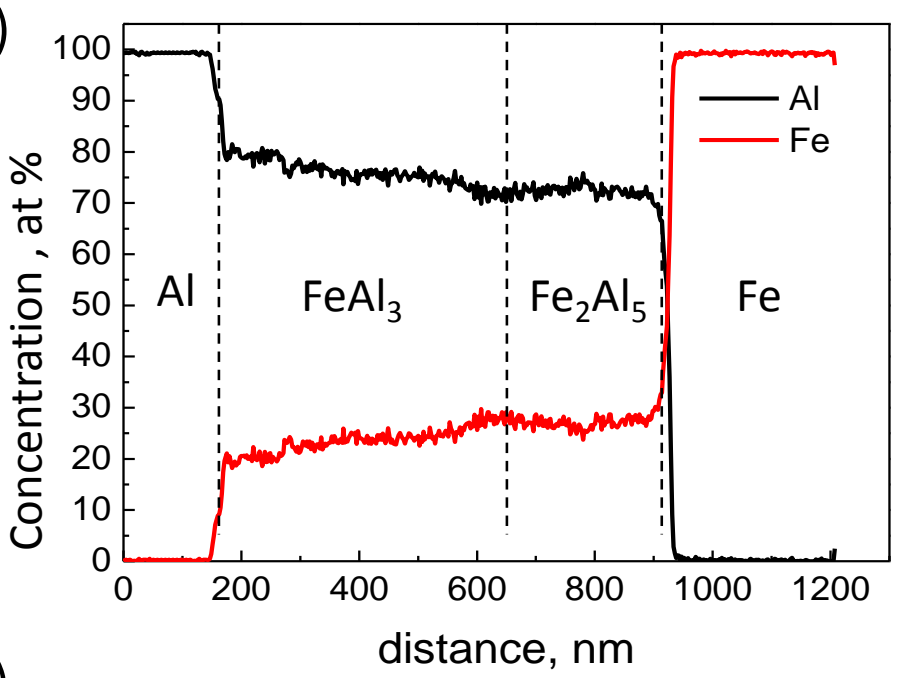

(b)

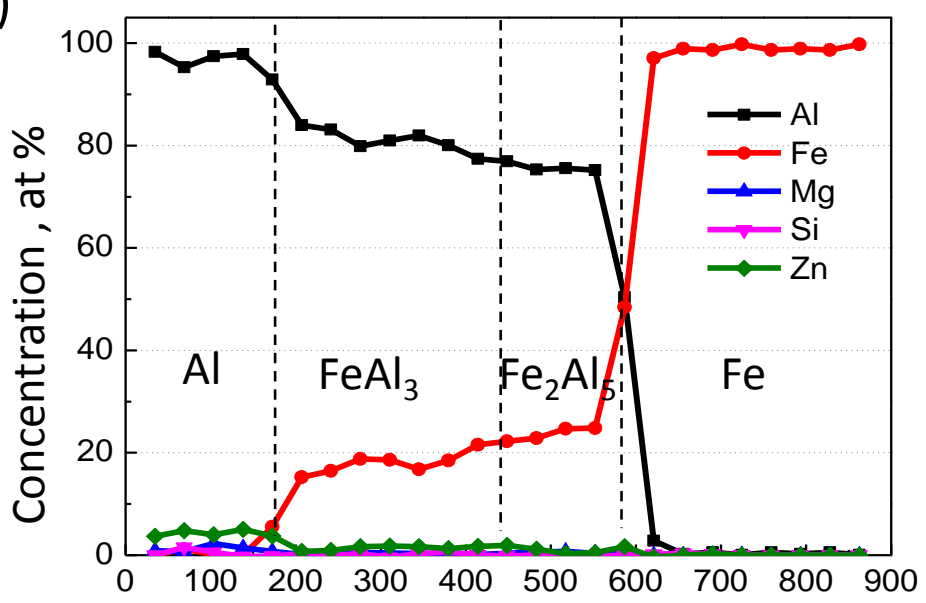

(c)

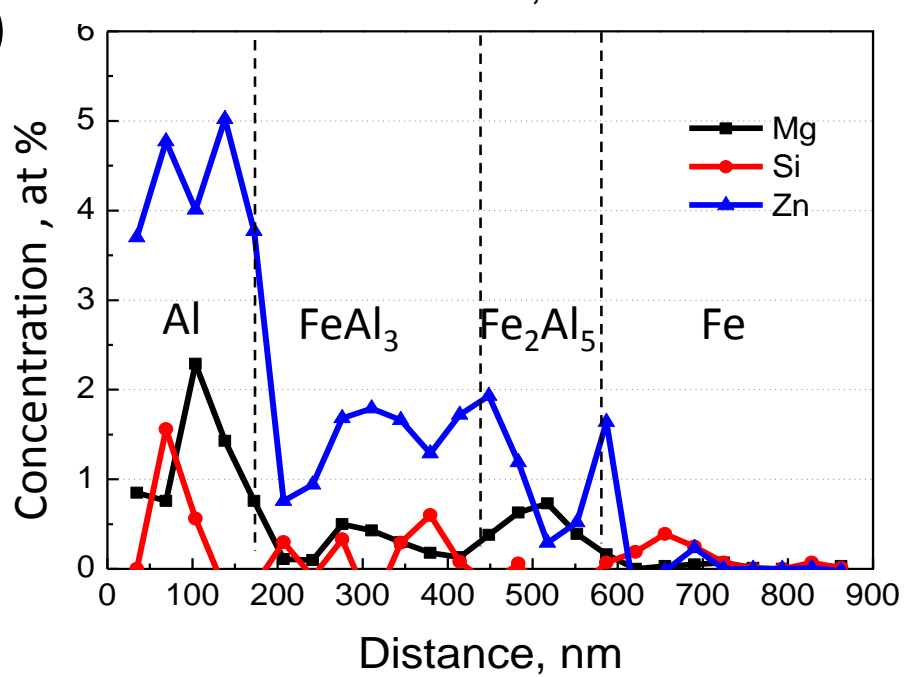

Fig. 7 Results from EDX composition line-scans obtained by TEM across the IMC interface layers for; (a) the AA6111-DC04 steel and (b) the AA7055-DC04 steel joints after a welding time of $1.5 \mathrm{~s}$. (c) Highlights the concentration of additional alloy elements (without Fe and Al) in the AA7055-DC04 joint using an expanded scale. The vertical dashed lines are the interface positions between different phases shown in the images, as obtained form the TEM images (Fig. 5). 

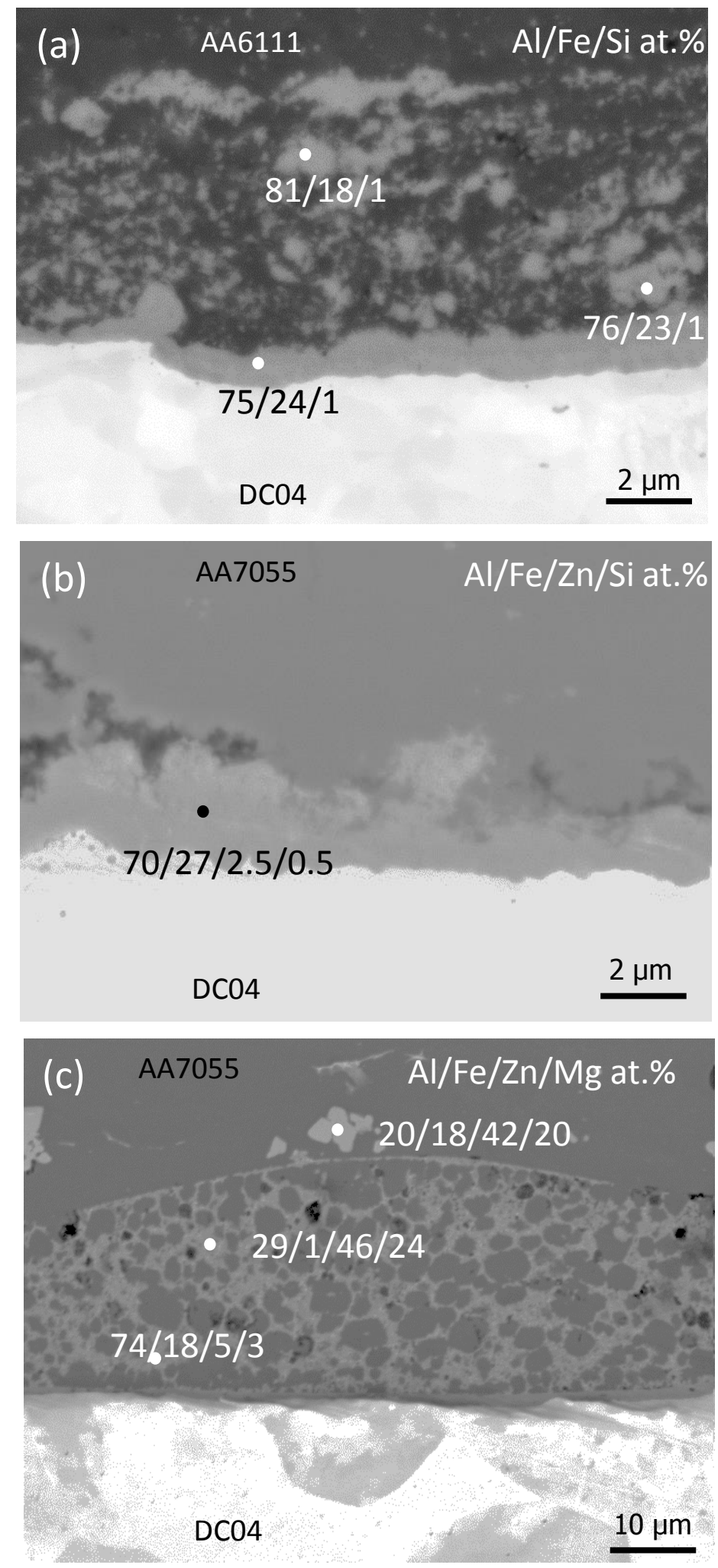

Fig. 8 Interface region microstructures observed at longer welding times for both material combinations; (a) AA6111-DC04 joints with a welding time of 2 seconds and the AA7055-DC04 material combination with welding times of (b) 1.5 and (c) 2 seconds. Examples from EDX point analysis results are provided at the positions indicated (refer to key in each image). 
(a)

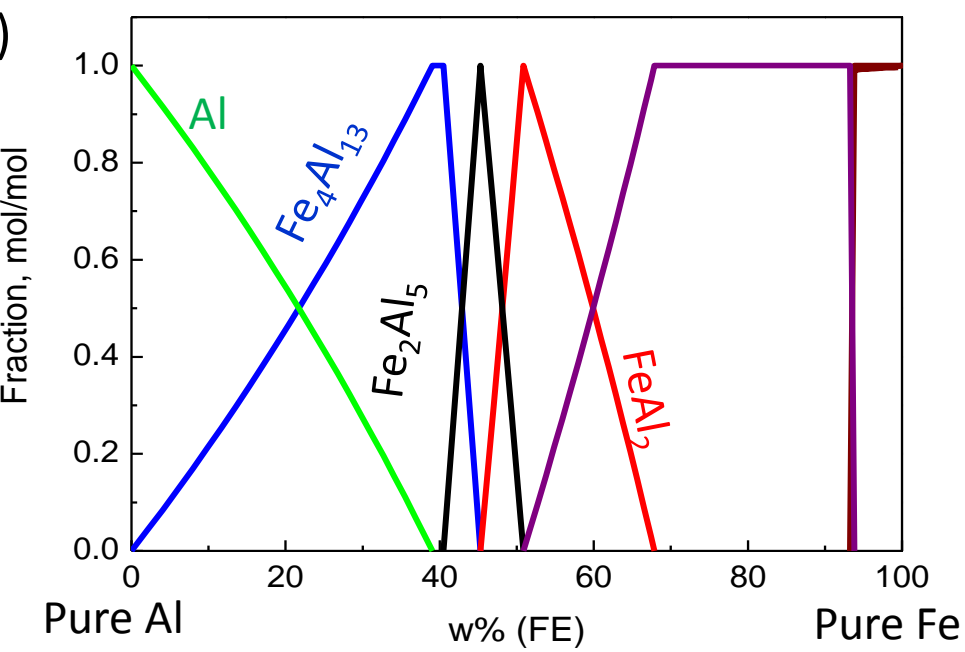

(b)

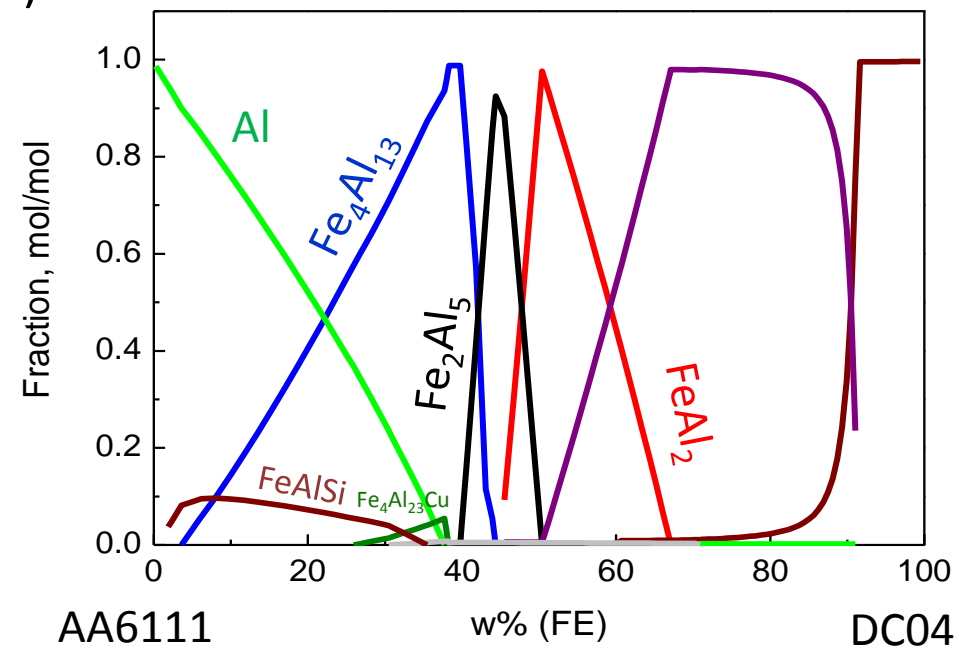

(c)

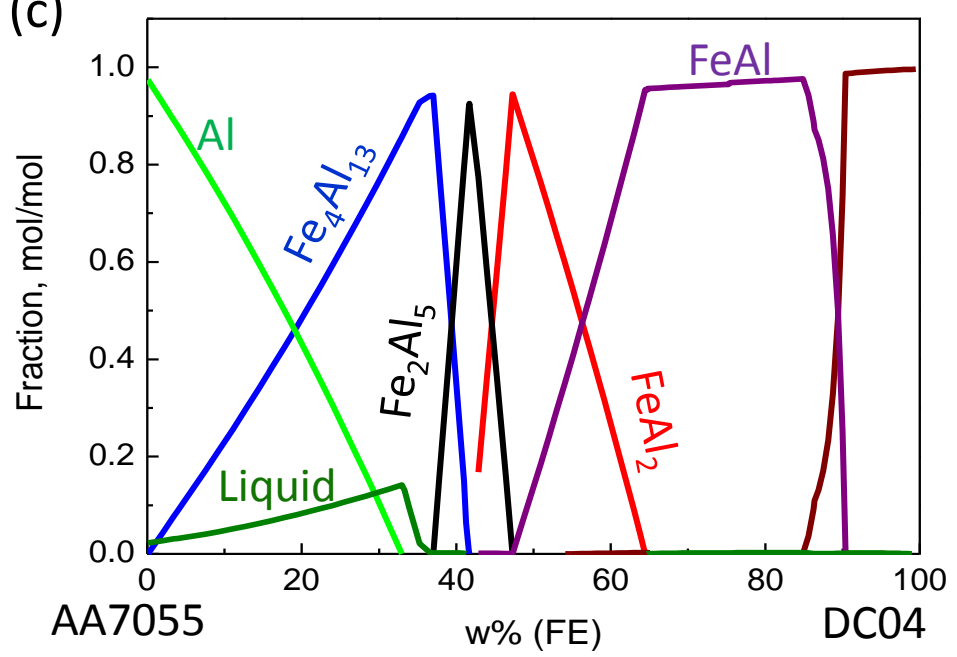

Fig. 9 CALPHAD predicted equilibrium phase fractions as a function of Fe content at $500^{\circ} \mathrm{C}$ for; (a) pure iron and aluminum, (b) AA7055-DC04 and (c) AA6111-DC04 steel. 

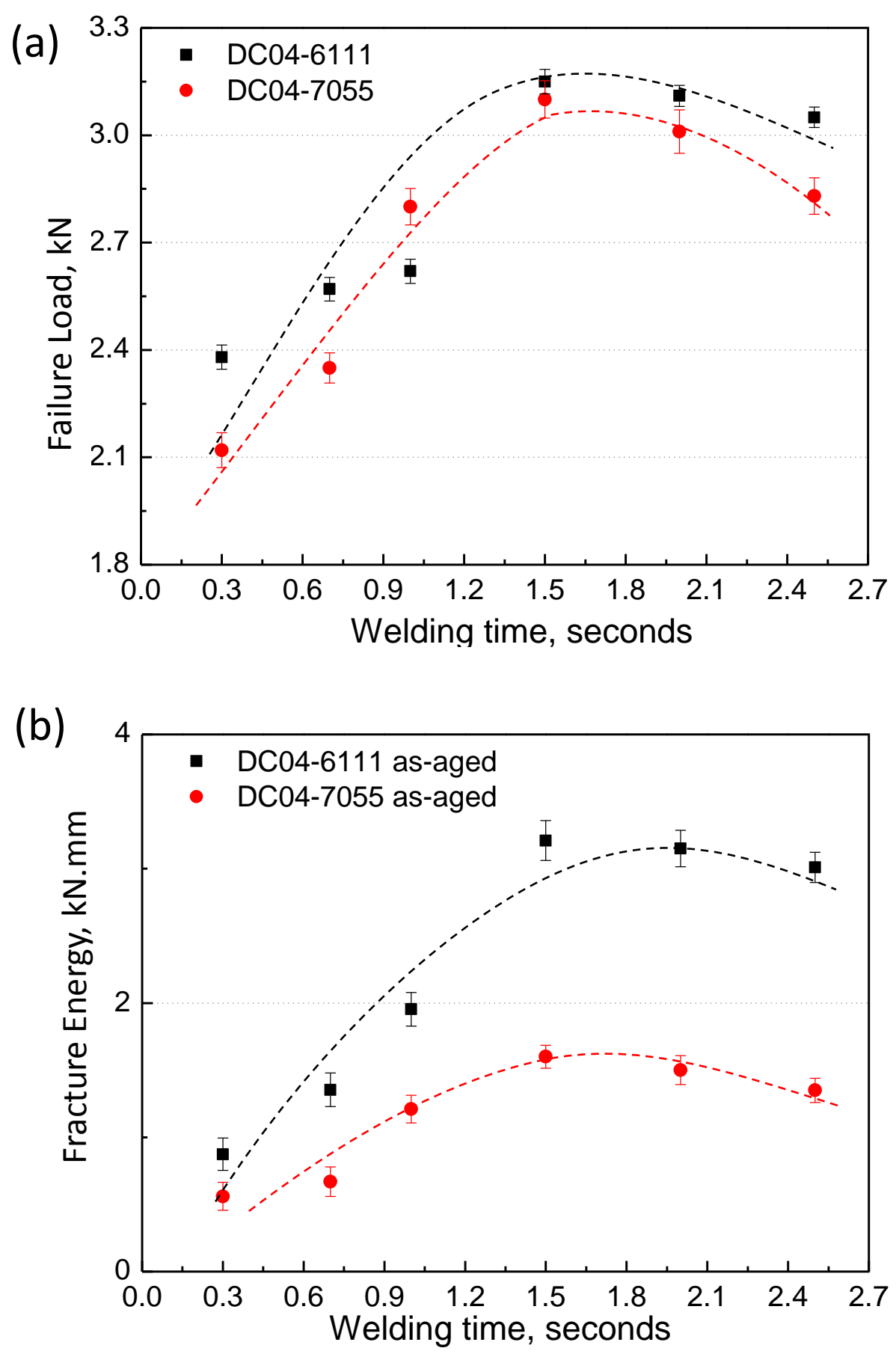

Fig. 10 Average (a) Failure loads and (b) fracture energies obtained from lap shear tests conducted on welds produced with both material combinations, as a function of welding time. 

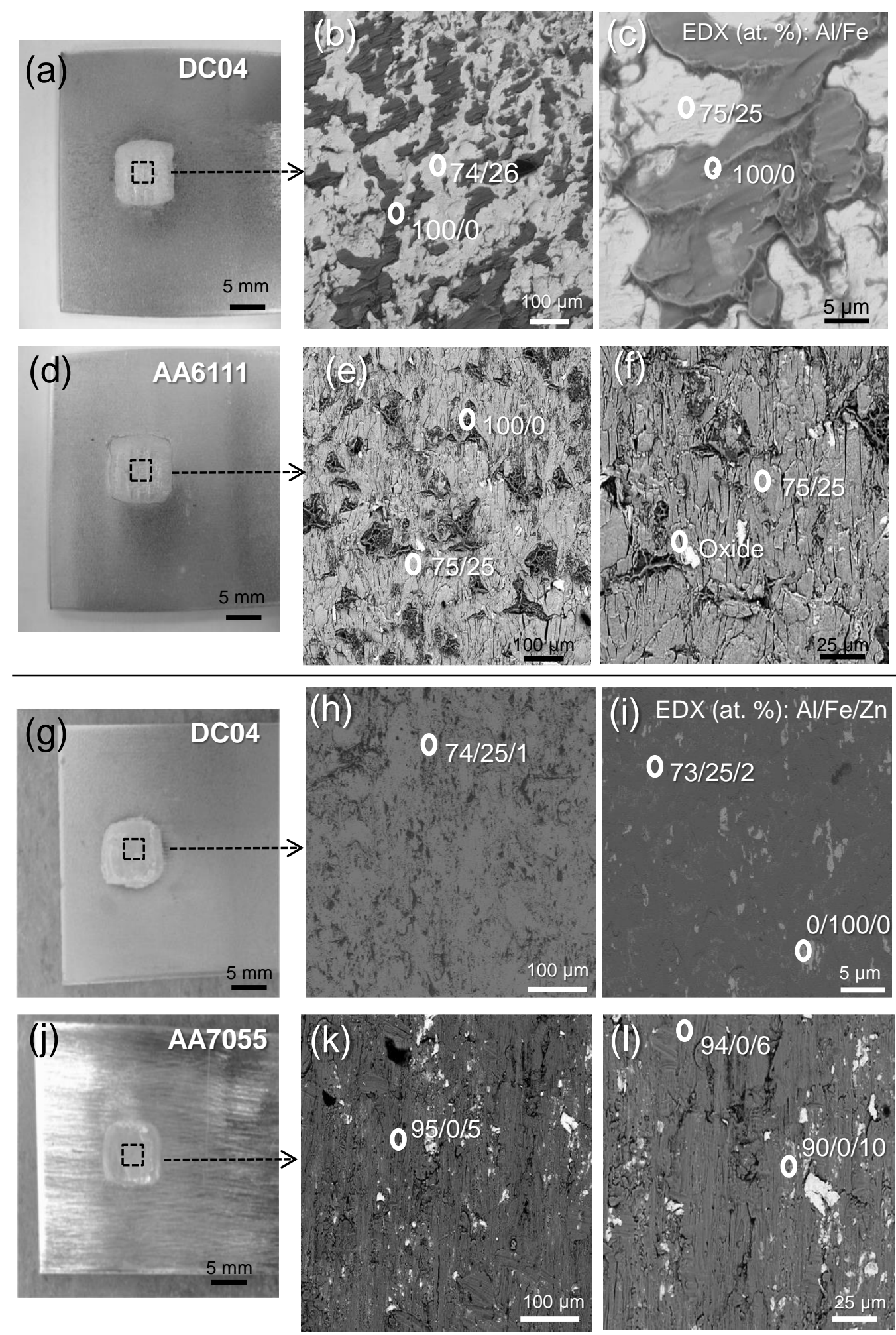

Fig. 11 Fracture surfaces of the peak lap shear strength samples (1.5 second welding time) showing; macro-images (a), (d) and ( $\mathrm{g})$, (j) of the steel and aluminum surfaces for the DC04-AA6111 and DC04-AA7055 weld combinations, respectively, with accompanying higher magnification SEM images from the regions highlighted in the macro-images of the steel side, (b) (c), (h) and (i), and the aluminium side of each joint in (e), (f), (k) and (l). Examples of the local composition of specific regions determined by EDX point analysis are indicated (refer to key in each image). 